\title{
Development of a brine treatment strategy for enhancing geothermal energy production and associated raw material extraction
}

\author{
VALENTIN M. GOLDBERG ${ }^{1}$, DANIEL WINTER ${ }^{2}$, FABIAN \\ NITSCHKE ${ }^{1}$, DIEGO MORATA ${ }^{3}$, JOACHIM \\ KOSCHIKOWSKI $^{2}$ AND THOMAS KOHL ${ }^{1}$ \\ ${ }^{1}$ Karlsruhe Institute of Technology \\ ${ }^{2}$ Fraunhofer Institute for Solar Energy Systems ISE \\ ${ }^{3}$ Universidad de Chile \\ Presenting Author: valentin.goldberg@kit.edu
}

The energy transition and the associated need for non-energy, mineral raw materials have prompted the German government to expand research and development activities along the entire value chain. It is well known that the highly mineralized thermal waters that circulate during the extraction of geothermal energy have, in some cases, significant enrichments of economically strategic elements such as lithium, rubidium, antimony or magnesium. The extraction of mineral resources from thermal waters is still challenging in terms of process technology, but new sustainable methods are paving the way for economic extraction as an alternative to conventional hard rock mining. Due to the overall high salt concentrations, selective separation of scale-forming minerals in a pretreatment stage is necessary to avoid scalings or membrane fouling in the later process steps. Furthermore, in high enthalpy geothermal fields, precipitation of amorphous silica is a limiting factor for the possible amount of extractable energy.

The focus of this study is on controlling silicate precipitation, which is expected to occur due to changes in temperature and pressure during energy and raw material extraction. The treatment and an associated precipitation process must be costeffective, integrable into the power plant process, and selective for silica for not affecting the valuable element content. In a multi-step and interdisciplinary process, a treatment strategy was developed and implemented in a large-scale prototype. In this study, the development of the silica processing strategy from laboratory to prototype design is described, as well as the possible integration into an operating geothermal power plant. Finally, the construction and implementation of a large-scale prototype with promising field results are presented. 